\title{
Sacral nerve stimulation for fecal incontinence
}

\author{
Isabel Pascual ${ }^{1,2}$, Carolina de Carlos González-Gómez ${ }^{3}$, Ricardo Ortega ${ }^{4}$, Marta Jiménez-Toscano ${ }^{5}$, \\ José Luis Marijuán ${ }^{3}$, Manuel Lomas-Espadas ${ }^{4}$, José María Fernández-Cebrián ${ }^{5}$, Damián García-Olmo ${ }^{3}$ \\ and José Antonio Pascual-Montero ${ }^{2,4}$
}

${ }^{1}$ Hospital Infanta Sofía, ${ }^{2}$ Clínica Cemtro, ${ }^{3}$ Hospital Universitario La Paz, ${ }^{4}$ Hospital Universitario 12 de Octubre, ${ }^{5}$ Hospital Universitario Fundación Alcorcón. Madrid, Spain

\begin{abstract}
Objective: to analyze short-term outcomes and complications for our first fifty patients with fecal incontinence undergoing sacral root stimulation.

Patients: fifty patients with fecal incontinence receiving sacral neuromodulation in 4 hospitals are reviewed. Discussed variables include: age, sex, incontinence duration, incontinence cause, prior surgery for incontinence, Wexner scale score, anorectal manometry parameters, and endoanal ultrasonographic findings. Following the procedure Wexner scale score, anorectal manometry parameters, and associated complications are reviewed.

Results: mean age of patients is 59.9 years, with females predominating. Most common causes of incontinence include obstetric procedures, idiopathic origin, and prior anal surgery. Mean followup is 17.02 months. Follow-up revealed a statistically significant reduction in Wexner scale score and increase in voluntary anal pressure. Technique-derived minor complications included: 2 surgical wound infections that led to stimulator withdrawal; 2 patients with pain who were managed conservatively; 1 case of externalization in a gluteal stimulator; and 1 broken tetrapolar electrode.

Conclusions: sacral nerve stimulation is a simple technique that improves Wexner scores in a statistically significant manner with a low complications rate.
\end{abstract}

Key words: Fecal incontinence. Anal sphincter. Anorectal manometry.

Pascual I, González-Gómez CC, Ortega R, Jiménez-Toscano M, Marijuán JL, Lomas-Espadas M, Fernández-Cebrián JM, GarcíaOlmo D, Pascual-Montero JA. Sacral nerve stimulation for fecal incontinence. Rev Esp Enferm Dig 2011; 103: 355-359.

Received: $12-01-11$

Accepted: 18-02-11.

Correspondence: Isabel Pascual Migueláñez. Clínica Cemtro. Avda. Ventisquero de la Condesa, 42. 28035 Madrid, Spain.

e-mail: isabelpasmi@hotmail.com

\section{INTRODUCTION}

Sacral nerve stimulation in the management of fecal incontinence has led to a change in the diagnostic and therapeutic algorithm for this disease in recent years (1-5). This treatment modality so far removed from the common practice of general surgeons has forced coloproctology specialists to undergo specific education on the technique's theoretical and practical aspects in order to treat their patients.

The procedure's absolute indication in fecal incontinence was initially focused on incontinent patients showing integrity of the sphincteric apparatus because of no previous lesions (idiopathic incontinence) or because of a prior sphincteroplaty procedure losing efficacy over time (incontinence most often resulting from obstetric trauma or prior surgery). Its indication has been gradually extended to patients with sphincteric defects (6-10), hence there is an ever increasing number of incontinent patients that are eligible for this procedure, also including stimulators indicated for constipation (11) and pain (12). As with all surgical skills, neuromodulation also displays a learning curve that may be shortened with workshops on stimulators and cadaveric training but cannot be obviated. The goal of this study was to analyze the first fifty cases by three general surgeon teams who used sacral root stimulations for the management of fecal incontinence, and to review the procedure's difficulties and short-term outcomes and complications.

\section{MATERIAL AND METHODS}

The first fifty patients with fecal incontinence treated with sacral nerve stimulation in four Madrid sites from 2004 to 2009 are retrospectively reviewed. All patients are adults (older than 18 years) with fecal incontinence refractory to medical treatment (diet and antidiarrheics) who accepted the procedure and signed an informed consent. The diagnostic protocol includes a clinical assessment using Wexner's 
Table I. Characteristics of patients with fecal incontinence receiving sacral root neuromodulation

\begin{tabular}{ll}
\hline Age (years) & 59.9 (range 38-85) \\
Sex & 44 women, 5 men \\
Duration (years) & 8.9 (range 1-35) \\
Cause of incontinence & \\
Obstetric & 19 \\
Idiopathic & 16 \\
Prior anal surgery & 8 \\
Low anterior resection & 2 \\
Multiple sclerosis & 2 \\
Rectal prolapse & 2 \\
Subtotal colectomy & 1 \\
Prior surgery & 4 sphincteroplasties \\
Wexner's scale (median) & 18 (range 8-20) \\
Anorectal manometry & \\
Resting pressure (mmHg) & 38.86 \\
Voluntary pressure (mmHg) & 68.4 \\
Threshold sensitivity volume (ml) & 25.5 \\
Maximum tolerated volume (ml) & 100.64 \\
Endoanal ultrasounds & \\
IAS injury & 8 \\
EAS injury & 5 \\
IAS and EAS injury & 10 \\
&
\end{tabular}

scale, anorectal manometry, endorectal US, and colonoscopy to rule out tumors and inflammation. Patients with a history of colon resection for tumors were excluded when their disease-free period was shorter than 5 years or when local or distant tumors persisted.

Variables analyzed include: age, sex, incontinence duration, cause of incontinence, prior surgery for incontinence, Wexner score, anorectal manometry parameters (resting pressure and voluntary contraction pressure, sensitivity threshold volume, maximum tolerated volume), and endoanal US findings (presence of a lesion in the internal anal sphincter, external anal sphincter, or both). Wexner scale, anorectal manometry parameters, and techniqueassociated complications are reviewed following the procedure.

A 2-4-week test period with a temporary stimulator was used for all patients by percutaneously placing a tetrapolar electrode (Medtronic, Minneapolis, USA) at the S3 or S4 foramen. The procedure was accomplished as ambulatory major surgery. The electrode is always placed by bilaterally puncturing S3 or S4 under local anesthesia (which is checked out radiographically), and then placing it on the side with better sensitive response (paresthesia in the genital and anal region) or motor response (non-voluntary anal contraction or plantar flexion of the big toe) with the lowest voltage.

Criteria for the placement of the definitive stimulator following a minimal period of two weeks include a decrease of at least $50 \%$ in weekly incontinence episodes or a decrease of at least $50 \%$ in days with incontinence a week, and the patient's wish to undergo the procedure following the test period. The definitive implant -InterStim (Medtronic, Minneapolis, USA)- is lodged in a subcutaneous pocket in the gluteus or abdomen as per patient characteristics, in the area with more fat tissue.

The statistical study is performed with Wilcoxon's test for paired data, and statistical significance is considered to be at $\mathrm{p}<0.05$.

\section{RESULTS}

Fifty patients with fecal incontinence are reviewed to whom sacral stimulation was suggested for the management of their disease. Mean patient age was 59.9 years (range 38-85) with a predominance of women (Table I). Most frequent causes include obstetric and idiopathic origins as well as prior anal surgery (4 for hemorrhoids, 2 for fissures, 1 for hemorrhoids and fissures, and 1 for fistula); $46 \%$ of patients had some sort of sphincteric lesion in the endoanal US at the time of stimulator placement. Eleven patients had previously received biofeedback sessions ( 10 sessions for each patient, after which the need for neuromodulation was assessed), and 4 with a history of obstetric trauma a prior sphincteroplasty has been carried out (in two of them a defect persisted in the external sphincter).

All patients received a tetrapolar electrode and temporary stimulator, but for two initial subjects the maneuver had to be repeated on two occasions because of technical difficulties (S3 foramen could not be found and a second attempt is made 1 year afterwards according to patient wishes. In both cases the electrode could be placed at S3 in this second attempt). The antibiotic prophylaxis regimen used is: amoxicillin-clavulanic $2 \mathrm{~g}$ i.v., cefazolin $2 \mathrm{~g}$ i.v., or piperacillintazobactam 4/0.5 g i.v., at site discretion.

In two out of fifty patients receiving a temporary stimulator no satisfactory response was obtained during the test period (a decrease of at least 50\% in weekly incontinence episodes or a decrease of at least $50 \%$ in incontinence days per week), hence no definitive stimulator is placed.

Median Wexner scale score was reduced from 18 to 4 after the procedure during a mean follow-up of 17.02 months (median follow-up of 13 months), a decrease that was statistically significant $(\mathrm{p}<0.01)$.

Anorectal manometry changes are described in figure 1 . Voluntary pressure increased after pacemaker implantation in a statistically significant manner $(\mathrm{p}<0.01)$.

Technique-associated complications were considered minor: 2 surgical wound infections leading to stimulator withdrawal, 2 cases with pain (one in the implant area and one in the right lower limb) that were managed conservatively, 1 gluteal stimulator externalization which led to reimplantation in the abdominal wall, and a broken tetrapolar electrode managed by contralaterally placing a new lead and the definitive stimulator (the patient manually rotated the pacemaker inside the subcutaneous pocket, and the lead wire was twisted until broken. A new gluteal, small- 
er pocket was performed, and the pacemaker was fixed with nonabsorbable suture to avoid mobilization).

Of all 50 patients proposed for sacral root stimulation as treatment for fecal incontinence, 45 perceived the procedure had been successful.

\section{DISCUSSION}

Sacral neuromodulation implantation for the treatment of fecal incontinence requires specific training for general surgeons and appropriate patient selection; however, the technique is easily reproducible. As discussed above, two early patients in the series could not have their S3 foramen found during the first attempt, and temporary electrodes were successfully placed after one year in both cases because of growing experience. No doubt, puncturing to find the $\mathrm{S} 3$ foramen is more difficult in early cases, and in our view two key aspects should be considered for success: staff with expertise in this technique, especially during early procedures, and radiographic guidance using radiology. On occasion, when the foramen is not found during the first attempt, guidance is easier with sacral radiography than anatomic hallmarks. In such difficult cases, nearly always obese patients, our group performs a reverse technique seeking the puncture site on the skin already knowing where $\mathrm{S} 3$ is.

In our series of fifty patients we had good responses during the test period for 48 , and the definitive stimulator was therefore implanted in $96 \%$ of tested patients. This high percentage of definitive implants may result from appropriate patient screening, although the procedure assessment time ensures that a definitive pacemaker is only implanted in subjects where the technique proved effective. For fecal incontinence with the etiologies described in our series we found no differences in success rates.

This is a procedure that in the reviewed literature has a low complication or adverse effects rate, including surgical site infection. The incidence of infection in our series was $4 \%$, a value similar to that described in other studies (range 1.6-10.8\%) (13,14). In both cases infection occurred after definitive pacemaker implantation and prompted its withdrawal. In one case the microbiological study of the withdrawn stimulator revealed infection with $S$. aureus. This is a minor complication with a serious impact, since infection led to stimulator withdrawal and should therefore be considered a technical failure. Most useful to prevent postoperative infection is likely an appropriate antibiotic regimen according to the sensitivity shown by most common pathogens in each center, and then an evaluation of the regimen's efficacy. Importantly, during tetrapolar electrode placement (first stage) two surgical fields should be isolated -on the one hand a clean field on the sacral region, where the $\mathrm{S} 3$ foramen will be searched; on the other hand the anal region should be visible to check whether the anal sphincter contracted during stimulation. While no manipulation is needed in this second field, which is only for visually ascer-

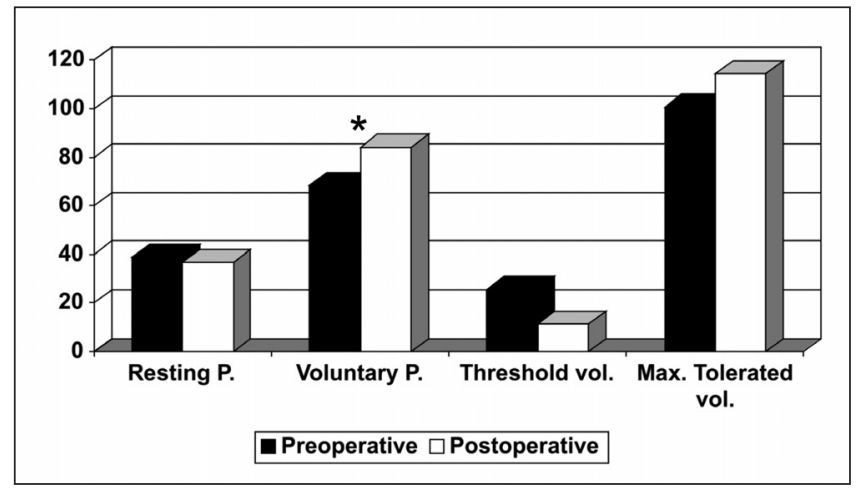

Fig. 1. Changes in anorectal manometry. Resting pressure, voluntary pressure, threshold volume, maximum tolerated volume. ${ }^{\star} p<0.05$.

taining motor responses, care should be taken not to contaminate instruments or surgeon hands, which may inadvertently touch this non-sterile area in their way to the puncture site. In the above-mentioned series (14), which discusses postoperative infection rates in 120 implanted patients, 5 of 13 cases with infection responded adequately to conservative therapy with antibiotics, whereas the rest had to have their stimulator explanted.

One complication we found in our series was a broken electrode. Stimulator malfunction is another potential complication reported in the literature: in our series it was due to a broken electrode in one patient and an exhausted battery in another subject, similar to descriptions by other authors (15). These two cases are in line with other reports that show the technique has no placebo effect, since incontinence recurs when the stimulator is off $(16,17)$.

The precise pathophysiological mechanism why the procedure is effective is unknown, and this may be seen in the medical literature for a variety of anorectal manometry values, both pre- and post-operatively, where various irreproducible effects are described for all series: increased maximum tolerated volume, increased volume at which sensation takes place, and increased sphincter resting pressure (18-21). In our study, following the procedure we saw that voluntary contraction pressure improved in a statistically significant manner. Despite such disparity in manometric results, all authors conclude that sacral neuromodulation is a highly effective approach for the management of fecal incontinence, no matter if manometric improvement was mediated by increased rectal capacity or higher sphincteric pressures (22). Thus, we believe this technique's usefulness may be assessed using continence scales or quality of life questionnaires, with no need for anorectal manometry during the postoperative period.

If we analyze treated patients with external sphincter lesion exclusively, Wexner score decreased from 17.08 to 3.6, and all perceived the procedure had been successful. Several authors have reported good results in this type of patients with non-repaired external sphincter $(23,24)$, and 
our experience confirms this. In our perspective two aspects remain to be defined along this line of work. The first one is knowing whether these favorable outcomes in the short term will persist over time. The second one is defining the place of sphincteroplasty (25) as a pre-neuromodulation step. However, further studies (with higher numbers of patients) with prior sphincter repair are needed to ascertain whether both groups evolve similarly long-term or previous external sphincter repair offers any benefits in the long run.

To conclude, sacral nerve stimulation is a simple technique with satisfactory clinical results in the management of anal incontinence for selected patients, with a low incidence of complications and easily documented by simply using Wexner's scale.

\section{REFERENCES}

1. Matzel KE, Kamm MA, Stosser M, Baeten CG, Christiansen J, Madoff R, and MDT-301 Group. Sacral spinal nerve stimulation for faecal incontinence: multicentre study. Lancet 2004;363:1270-6.

2. Matzel KE, Stadelmaier U, Hohenberger W. Innovations in fecal incontinence: sacral nerve stimulation. Dis Colon Rectum 2004;47:1720-8.

3. Wexner SD, Coller JA, Devroede G, Hull T, McCallum R, Chan M, et al. Sacral nerve stimulation for fecal incontinence: results of a 120patient prospective multicenter study. Ann Surg 2010;251:441-9.

4. Muñoz Duyos A, Navarro Luna A. Sacral root stimulation in the treatment of faecal incontinence. Cir Esp 2010;87:271-2.

5. Navarro JM, Arroyo Sebastián A, Pérez Vicente F, Sánchez Romero AM, Pérez Legaz J, Serrano Paz P, et al. Sacral root neuromodulation as treatment for fecal incontinence. Preliminary results. Rev Esp Enferm Dig 2007;99:636-42.

6. Dudding TC, Parés D, Vaizey CJ, Kamm MA. Sacral nerve stimulation for the treatment of faecal incontinence related to dysfunction of the internal anal sphincter. Int J Colorectal Dis 2010;25:625-30.

7. Ratto C, Litta F, Parello A, Donisi L, Doglietto GB. Sacral nerve stimulation is a valid approach in fecal incontinence due to sphincter lesions when compared to sphincter repair. Dis Colon Rectum 2010;53:264-72.

8. Chan MK, Tjandra JJ. Sacral nerve stimulation for fecal incontinence: external anal sphincter defect vs. intact anal sphincter. Dis Colon Rectum 2008;51:1015-24.

9. Jarrett ME, Dudding TC, Nicholls RJ, Vaizey CJ, Cohen CR, Kamm MA. Sacral nerve stimulation for fecal incontinence related to obstetric anal sphincter damage. Dis Colon Rectum 2008;51:531-7.
10. Boyle DJ, Knowles CH, Lunniss PJ, Scott SM, Williams NS, Gill KA. Efficacy of sacral nerve stimulation for fecal incontinence in patients with anal sphincter defects. Dis Colon Rectum 2009;52:1234-9.

11. Kamm MA, Dudding TC, Melenhorst J, Jarrett M, Wang Z, Buntzen $\mathrm{S}$, et al. Sacral nerve stimulation for intractable constipation. Gut 2010;59:333-40.

12. Govaert B, Melenhorst J, van Kleef M, van Gemert WG, Baeten CG. Sacral neuromodulation for the treatment of chronic functional anorectal pain: a single center experience. Pain Pract 2010;10:49-53.

13. Michelsen HB, Thompson-Fawcett M, Lundby L, Krogh K, Laurberg S, Buntzen S. Six years of experience with sacral nerve stimulation for fecal incontinence. Dis Colon Rectum 2010;53:414-21.

14. Wexner SD, Hull T, Edden Y, Coller JA, Devroede G, McCallum R, et al. Infection rates in a large investigational trial of sacral nerve stimulation for fecal incontinence. J Gastrointest Surg 2010;14:1081-9.

15. Faucheron JL, Voirin D, Badic B. Sacral nerve stimulation for fecal incontinence: causes of surgical revision from a series of 87 consecutive patients operated on in a single institution. Dis Colon Rectum 2010;53:1501-7.

16. Mowatt G, Glazener C, Jarrett M. Sacral nerve stimulation for fecal incontinence and constipation in adults: a short version Cochrane review. Neurourol Urodyn 2008;27:155-61.

17. Jarrett ME, Mowatt G, Glazener CM, Fraser C, Nicholls RJ, Grant AM, et al. Systematic review of sacral nerve stimulation for faecal incontinence and constipation. Br J Surg 2004;91:1559-69.

18. Kenefick NJ. Sacral nerve neuromodulation for the treatment of lower bowel motility disorders. Ann R Coll Surg Eng 2006;88:617-23.

19. Michelsen HB, Buntzen S, Krogh K, Laurberg S. Rectal volume tolerability and anal pressures in patients with fecal incontinence treated with sacral nerve stimulation. Dis Colon Rectum 2006;49:1039-44.

20. Rasmussen OO, Buntzen S, Sorensen M, Laurberg S, Christiansen J. Sacral nerve stimulation in fecal incontinence. Dis Colon Rectum 2004;47:1158-63.

21. Ciriza de los Ríos C, Ruiz de León San Juan A, Díaz-Rubio García M, Tomás Moros E, García Durán F, Muñoz Yagüe T, et al. Differences in the pressures of canal anal and rectal sensitivity in patients with fecal incontinence, chronic constipation and healthy subjects. Rev Esp Enferm Dig 2010;102:683-90.

22. Melenhorst J, Koch SM, Uludag O, van Gemert WG, Baeten CG. Sacral neuromodulation in patients with faecal incontinence: results of the first 100 permanent implantations. Colorectal Dis 2007;9:725-30.

23. Dudding TC, Parés D, Vaizey CJ, Kamm MA. Predictive factors for successful sacral nerve stimulation in the treatment of faecal incontinence: a 10-year cohort analysis. Colorectal Dis 2008;10:249-56.

24. Melenhorst J, Koch SM, Uludag O, van Gemert WG, Baeten CG. Is a morphologically intact anal sphincter necessary for success with sacral nerve modulation in patients with faecal incontinence? Colorectal Dis 2008;10:257-62.

25. Altomare DF, De Fazio M, Giuliani RT, Catalano G, Cuccia F. Sphincteroplasty for fecal incontinence in the era of sacral nerve modulation. World J Gastroenterol 2010;16:5267-71. 